DRAFT (Paper Accepted for Publication)

\title{
Four Decades of Support for Artisanal and Small-Scale Mining in Sub-Saharan Africa: A Critical Review
}

\author{
Gavin Hilson* and James McQuilken
}

Faculty of Business, Economics and Law, University of Surrey, Guildford GU2 7XH, United Kingdom

* Corresponding author Phone: +44 (0)1483 686326 Email: g.m.hilson@ surrey.ac.uk 


\section{DRAFT (Paper Accepted for Publication)}

\section{Abstract}

This review reflects critically on why, despite its growing economic importance, artisanal and small-scale (ASM) - low-tech, labour-intensive mineral extraction and processing - occupies such a peripheral position on the economic development agenda of sub-Saharan Africa. A poor understanding of the sector's role in the region's liberalized economies has certainly contributed to this oversight; as has the strong influence, at the policymaking level, of unfounded ideas and generalizations about the sector's activities. After providing a brief overview of ASM in sub-Saharan Africa, the paper explores why the sector has yet to make a mark on the region's local economic development agenda and feature prominently in its poverty alleviation strategies.

Keywords: artisanal and small-scale mining (ASM); sub-Saharan Africa (SSA); poverty; livelihoods 


\section{DRAFT (Paper Accepted for Publication)}

\section{Introduction}

Why does artisanal and small-scale mining (ASM) - the low-tech, labour-intensive mineral extraction and processing found across the developing world - continue to be overlooked in most international, regional and local economic policies and programs? Despite surfacing on the international development agenda over four decades ago, the sector has yet to capture the attention of donor agencies, NGOs and host governments. Nowhere has this been more evident than in sub-Saharan Africa, where ASM provides direct employment to tens of millions of people and has created innumerable economic opportunities for many millions more in the downstream industries it has spawned. ${ }^{1}$

This paper reflects critically on why, despite its growing economic importance, ASM occupies such a peripheral position on the economic development agenda of sub-Saharan Africa. A poor understanding of the sector's role in the region's liberalized economies has certainly contributed to this oversight; as has the strong influence, at the policymaking level, of unfounded ideas and generalizations about the sector's activities. A growing body of evidence (Barry 1996; UNECA 2003; Fisher 2007) which points to ASM having alleviated significant rural hardship, reinvigorated deteriorating smallholder farming activities, catalyzed the growth of infrastructure and reduced rural-urban migration across sub-Saharan Africa has failed to energize a donor agenda that continues to promote archaic policies and measures to facilitate local economic development. After providing a brief overview of ASM in sub-Saharan Africa, the paper comes to grips with why the sector has yet to make a mark on the region's local economic development agenda and feature prominently in its poverty alleviation strategies.

\section{Artisanal and Small-Scale Mining in sub-Saharan Africa: A Snapshot}

Nearly three decades ago, the World Bank published the landmark report, Small-Scale Mining: A Review of the Issues (Noetstaller, 1987). The organization relied heavily on this document for guidance throughout the 1990s, when several ambitious multimillion dollar mining sector reform programs and restructuring projects were commissioned across sub-Saharan Africa.

Importantly, Small-Scale Mining: A Review of the Issues drew attention, for the first time, to how ASM could potentially be an important source of jobs. It begins by reflecting abstractly on the economic importance of small-scale industries in developing countries, making the case that 'a highly beneficial attribute of small enterprises for developing countries is that they are more labor-intensive than large firms and thus account for an appreciably larger share of recorded employment'. It furthermore argues that 'The same is true for small mining operations which frequently employ large numbers of workers in rural mining districts, where job opportunities are particularly scarce' (p. 13). The document is peppered with business vernacular, making use of such words and phrases as 'entrepreneurship', 'business development' and 'small enterprise', language which captures the essence of the policy mind-set at the time: namely, the view that ASM is populated largely by people in search of business opportunities and looking for quick returns on investment.

The literature that has since emerged, however, provides a much more comprehensive picture of the sector, grounded in empirical findings collected in ASM communities. This body of analysis establishes, inter alia, that - at least in sub-Saharan Africa - the sector's activities are much more complex than the diagnosis offered by Noetsteller (1987). Crucially, the evidence presented in the literature over the past two decades suggests that poverty, not a desire to 'get rich quickly', is driving most people into ASM and fuelling its rapid expansion in all corners of rural sub-Saharan Africa. Countless studies (e.g. Banchirigah 2006; Spiegel, 2009; Hilson 2010; Banchirigah and Hilson, 2010) have made this link, pointing to how the structural adjustment programs and widespread neo-liberal economic reforms implemented across the region in the late-1970s and early-1980s led to the downsizing of industries, crippled smallholder farmers, and initiated a pruning of the public sector. The region's ASM economy and the downstream industries it has spawned have absorbed scores of otherwise-unemployed people who were adversely affected by these changes.

To date, no comprehensive census has been carried out on ASM, so there is no clear idea on how many people are employed directly in the sector. Table 1 lists ASM employment estimates for selected countries in sub-Saharan Africa. Most are general projections based on surveys conducted by development agencies in villages, and are extremely conservative estimates overall. Most notably, the figure supplied by the ILO (ILO, 1999) for the size of the global ASM workforce - 13 million - may, from what little data are available, apply to

\footnotetext{
${ }^{1}$ There are countless minerals mined on a small-scale, including diamonds, gemstones, bauxite and columbitetantalite (Maconachie, 2009; Kamlongera and Hilson, 2011; Bleischwitz et al., 2012). The majority of ASM operators, however, are engaged in the extraction of precious metals and stones, although gold, being the most ubiquitously-occurring geologically, is by far the most popular mineral being mined. An estimated 10 percent of the world's gold originates from the ASM sector (UNECA, 2011). The paper focuses primarily on artisanal and small-scale gold mining.
} 


\section{DRAFT (Paper Accepted for Publication)}

West Africa alone. But it is the downstream employment which ASM creates where most of its 'job creation' takes place. There are an estimated six downstream jobs 'created' per individual employed directly in the sector, a list of occupations which includes service people, such as taxi drivers, cooks and clothing merchants; semi-skilled labourers, including machine operators and repairmen; and skilled and educated groups, notably bookkeepers, accountants and technicians.

The bulk of discussion on ASM to date has emphasized its negative attributes (ILO, 1999; Hentschel et al., 2002; Speigel and Veiga, 2010). In addition to its activities being responsible for defacing vast tracts of landscape and, in the case of gold panning, releasing significant quantities of mercury pollution into the natural environment, operators and employees often work in hazardous and unhygienic conditions. Moreover, many ASM communities - including several across sub-Saharan Africa - have become 'hotspots' for prostitution, disease and narcotics consumption. These 'ills' have captured the attention of journalists, government officials and to some extent, donors, many of whom portray ASM in an extremely negative light, in the process influencing and at times manipulating a poorly-informed general public. It is now fashionable in various media outlets and public forums to discuss at length ASM's problematic side: its perceived child labour problem (Hilson, 2008; Free the Slaves, 2013; Human Rights Watch, 2013); the 'hit and miss' gold panning activities which leave large quantities of mercury into local streams and soils (Bank of Ghana, 2003; Human Rights Watch, 2013); and how producing communities play host to a range of sexually transmitted diseases (ILO 1999; Hentschel et al., 2002). But lost in these discussions, many of which are one-sided and superficial in their assessment, has been the sector's positive impacts - namely, its contribution to employment and production.

Perhaps more importantly, the problems which have come to be associated ASM are, in many ways, 'expressions' of its perpetual informality (after Hilson, 2013). Most ASM activities are unlicensed, and therefore not monitored and financed through legitimate channels. This is particularly the case in sub-Saharan Africa, where, as will be explained in subsequent sections of this paper, efforts to bring ASM activities into the legal domain have been noticeably ad hoc. For the region's operators, many of whose setups are among the most rudimentary in the world, a lack of security of tenure has had serious implications for the environment and local quality of life: focusing on securing enough money for their daily needs, few likely view the very impacts of their activities, which the general public, donors and policymakers see as problems, as priority concerns. Working under very difficult conditions, the region's artisanal and small-scale miners have, no surprisingly, struggled to accumulate incomes and improve their livelihoods. Forced to secure finances through informal means and without access to efficient equipment, many become trapped in a vicious cycle of poverty (Figure $1)$.

Figure 1: The ASM poverty trap

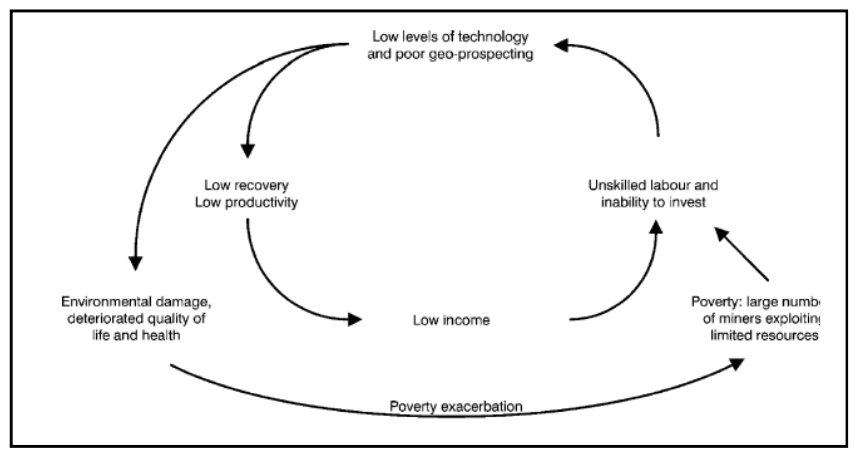

Source: Hilson and Pardie, 2006

Why have the region's miners struggled to escape this trap, and what have governments and donors done to tackle the problem? Moreover, why is ASM in sub-Saharan Africa in the state it is - as a largely informal, environmentally-degrading and characterized by poor working conditions - and how in tune are policymakers with the needs of individual operators and their struggles? As the discussion that follows explains, donor support has failed to improve the livelihoods of the region's artisanal and small-scale miners, largely because, over the course of the past four decades, a string of inappropriate sector-specific programs and policies have been implemented, for the most part independently of core country-level and regional development efforts. Whilst the attitudes of governments and donors toward ASM in sub-Saharan Africa has changed noticeably over this period, failure to integrate industry concerns into major rural poverty alleviation efforts from the beginning explains why discussions about the sector's needs continue to have so little traction in policymaking dialogues today. 
DRAFT (Paper Accepted for Publication)

Table 1: Estimates of ASM employment and dependents in selected African countries

\begin{tabular}{|c|c|c|}
\hline Country & $\begin{array}{l}\text { Directly Working in } \\
\text { ASM }\end{array}$ & $\begin{array}{l}\text { Estimated Number of } \\
\text { Dependents }\end{array}$ \\
\hline Angola & 150,000 & 900,000 \\
\hline Burkina Faso & 200,000 & $1,000,000$ \\
\hline $\begin{array}{l}\text { Central African } \\
\text { Republic }\end{array}$ & 400,000 & $2,400,000$ \\
\hline Chad & 100,000 & 600,000 \\
\hline Côte d'Ivoire & 100,000 & 600,000 \\
\hline $\begin{array}{l}\text { Democratic Republic of } \\
\text { the Congo }\end{array}$ & 200,000 & $1,200,000$ \\
\hline Eritrea & 400,000 & $2,400,000$ \\
\hline Ethiopia & 500,000 & $3,000,000$ \\
\hline Ghana & $1,100,000$ & $4,400,000$ \\
\hline Guinea & 300,000 & $1,500,000$ \\
\hline Liberia & 100,000 & 600,000 \\
\hline Madagascar & 500,000 & $2,500,000$ \\
\hline Malawi & 40,000 & - \\
\hline Mali & 400,000 & $2,400,000$ \\
\hline Mozambique & 100,000 & $1,200,000$ \\
\hline Niger & 450,000 & $2,700,000$ \\
\hline Nigeria & 500,000 & $2,500,000$ \\
\hline South Africa ${ }^{2}$ & 20,000 & - \\
\hline Sierra Leone & 300,000 & $1,800,000$ \\
\hline Sudan & 200,000 & $1,200,000$ \\
\hline Tanzania & $1,500,000$ & $9,000,000$ \\
\hline Uganda & 150,000 & 900,000 \\
\hline Zimbabwe & 500,000 & $3,000,000$ \\
\hline
\end{tabular}

Sources: Data extracted from Dreschler (2001), Mutemeri and Petterson (2002), and UNECA (2011)

\section{In the Beginning...}

Why, during the years following publication of Small-Scale Mining in the Developing Countries, did ASM fail to gain much traction in development and economic plans and policies, particularly in sub-Saharan Africa? In hindsight, this was, indeed, a missed opportunity because the donor agenda was in transition at the time: the overall approach taken to deliver aid was being 'rethought'. As Lancaster (1999) recalls, most 'aid donors during the 1960 s and 1970 s began to deal directly with spending ministries as they prepared and 


\section{DRAFT (Paper Accepted for Publication)}

implemented their projects', an arrangement which saw 'an aid donor typically conceiv[ing] a project (often based on the development priorities prevailing in the donor's capital) and propos[ing] it to the appropriate spending ministry' (p. 31). The world's bilateral and multilateral lending institutions certainly seemed open to new ideas.

Had ASM entered the dialogue at this early stage, it would have likely become a focal point in many of the more important development debates at the time, largely because of the very significant observations made in Small-Scale Mining in the Developing Countries (UN, 1972). If elucidated further, these ideas could have quite easily facilitated a change in public perception toward ASM in the early going. Notably, in addition to pointing out that 'the jobs, pay-rolls, spending, taxes etc...even in the case of small-scale mining, are quite significant to a developing country', this landmark document drew attention to how 'small-scale mining offers the subsistence agricultural labourer an introduction to and training in a money economy without uprooting him from his accustomed social environment, since the employment would be local'. Similar phenomena including observations that the sector provides numerous employment opportunities, and that revenues accrued from its production help to nourish subsistence farming activities - were later reported in a host of documents (e.g. Barry 1996; UN 1996; ILO 1999), albeit rather cursorily. Failure to substantiate, with hard data, these points, most of which are only mentioned briefly in the document, likely led to their immediate dismissal; they would not be explored in any considerable depth for another three decades.

With no influential body such as the UN to lobby donor partners and policymakers, most government officials continued to view ASM as an entrepreneurial activity and little else, a position which did not mesh with the ideologies underpinning aid strategies. Specifically, there was little chance of the sector receiving much attention at a time when Robert McNamara, then President of the World Bank, was promoting 'integrated rural development'. McNamara was fixated on mobilizing African leaders to 'lead an assault on rural poverty by improving agriculture' (Eicher, 2003, p. 15), whilst simultaneously reshaping the Bank's donor strategy to prioritize large-scale project development. One important manifestation of the latter, in the case of 1980s and 1990s sub-Saharan Africa, was a liberalized large-scale mining economy propelled by foreign investment (World Bank 1992, Weber-Fahr, 2002).

A small pool of ASM experts were chiefly responsible for failing to put the sector 'on the map' from the beginning. Rather than devoting the necessary time to explore the potential role ASM could play in development, experts became fixated on the more mundane. This included attempting to define 'artisanal mining' and 'small-scale mining' in international policy documents, in hindsight fruitless efforts which effectively derailed any chance of the sector gaining any currency in mainstream development dialogues. The entire first chapter of Small-Scale Mining in the Developing Countries, 'The technical and economic characteristics of small-scale mining', seemed to have set the tone. It describes the main characteristics of 'small-scale mining', presenting data on production, employment and technology in an attempt to calibrate thinking on the sector and develop appropriate universal definitions. The issues tackled in the chapter prompted UN officials to organize a series of international seminars to explore in greater detail many of these same ideas, the largest and indeed most significant gatherings being the International Conference on the Future of SmallScale Mining in Jurica (Mexico) in 1978, and Strategies for small-scale mining and mineral industries, in Mombasa (Kenya) in 1980. These meetings, however, did little to advance understanding of the sector's crucial livelihoods dimension, leading a number of scholars to question, several years later, both the timing of and decision to organize these events altogether. Two of the harshest assessments were delivered by Jennings (2003), who mused over what he described as the 'essentially futile attempts to define and compartmentalize small-scale mining in the 1970s' (p. 156), and Hollaway, who rather cynically reported that experts at the time were meeting 'to define what it is they were talking about' (p. 35).

These events were not entirely futile because they drew attention to ASM for the first time and would yield valuable publications which would provide a fair level of detail about the characteristics of the sector's activities. But at the same time, they did little to ignite a critical 're-conceptualization' of the sector. By focusing almost exclusively on the industry's characteristics and attempting to tackle definitional challenges, these events would be a major disservice to ASM, distancing it even further from the mainstream global international development agenda. A preoccupation with these tasks seemed to inhibit more dynamic thinking about the sector's operators and activity.

Ironically, at the time when, in the words of Jennings (2003) 'essentially futile attempts' were being made to define ASM, mining more generally was beginning to take on a very different role in development, a change captured in the World Bank's landmark report, The Mining Industry and the Developing Countries (Bosson and Varon, 1978). It accurately pointed out at the time that, 'substantial benefits can accrue to a country from a properly structured and administered mineral industry' - specifically, that 'in addition to providing foreign exchange earnings, mining activity may produce additional revenue through taxes and royalties; stimulate development of depressed regions; improve the professional and technical skills of nationals; and, for some countries, provide a nucleus for economic development' (p. 7). Thus began a large donor-funded effort which sought to revitalize mining activities in the developing world. The exercise began in Latin America 


\section{DRAFT (Paper Accepted for Publication)}

which, unlike sub-Saharan Africa, had in place fairly robust mineral codes and policies. In the late-1970s and early-1980s, a series of World Bank-funded projects were implemented in all corners of the region, the blueprints for each a reflection of the general thinking at the time: that small-scale mining was populated by entrepreneurs and little more than a capable business venture if properly supported.

On the one hand, there were projects that sought to transform ASM into something that it was not, and, because of the growing presence of competing multinationals, could likely never become: an export-based industry propelled by, and appealing to, foreign investors. Such was the case with the US\$7.5 million Bolivia National Mineral Exploration Fund Project, 1979. It proved to be little more than an exercise aimed at bolstering production at resident small-scale mines judged to be 'rather primitive, have low productivity, and employ little capital and low levels of technologies' (World Bank, 1979, p. 6), and better positioning operators to secure investment. It aimed to correct what was seen by Bank officials as 'past efforts to inject capital into the small mining sector' which 'achieved very little, mostly because it was not accompanied by appropriate technical assistance' (p. 7). The monies were sought to transform the National Exploration Fund (FNEM), a policy mechanism established by the Bolivian Government to finance mineral prospecting and exploration activities, into an autonomous public development enterprise, for the sole purpose of facilitating an increase in small-scale mining activity in the country.

Recognizing that 'international mining companies... are increasingly reluctant to undertake exploration in developing countries for reasons of perceived political risk, as well as possible inadequate financial gains' ( $p$. 10), World Bank officials were clearly encouraging the Bolivian Government to take action. They drew attention to how 82 applications for exploration financing had been received from small and medium-scale mining companies during the 22 months prior to the proposal's submission. The shortcomings of such exercises, however, have long been highlighted: specifically, how 'many projects to assist small-scale mining have failed or have not led to lasting improvements because they have treated small-scale mining as a subset of large, formal mining' (ILO, 1999, np). To its credit, the World Bank did, in fact, point out at the time that in many corners of the developing world, ASM 'requires special attention when formulating policies and drafting mineral and fiscal legislation, when staffing the ministries, and when preparing a mining sector development plan' (1978, p. 264). But it seems that many host governments have viewed the situation very differently, believing that the sector could, indeed, serve as a foundation for export-led growth.

On the other hand, there was a host of projects launched that had ASM at their core but which, significantly, did little to advance understanding of its importance in the rural societies of the developing world where it occurred, as well as its interconnectedness with other economic activities. These projects, rather, in the spirit of entrepreneurialism, sought to bolster investment in the sector, and foster economic and technical support for activities. One of the more illustrative examples of this was the application put forward by the Mexican Government to the World Bank for US\$40 million (World Bank, 1980) to 'finance the foreign exchange cost of a Small and Medium-Scale Mining Development project' on the grounds that 'Small and medium-size mining concerns have traditionally been the origin of large mining operations in Mexico' (p. 18). The Bank was called upon to 'provide financial and technical assistance to small and medium-size enterprises in the mining sector to help expand their exploration, mine development and production programs and...support the institutions assisting mining enterprises' (p. 14). Further justification for the case was based around 'the fragmented and varied nature of the country's geological resources, or high ore grades, and of the relatively low cost of labor which enable smaller mines to compete more or less effectively with capital-intensive operators', and how 'historically, most of the larger mining concerns had their origin in small mines which used increasingly larger and more efficient mineral beneficiation facilities' (p. 9). Such projects, however, began to lose favour with the World Bank toward the end of the 1970s, a time when again, officers began promoting often, with reckless abandon - the organization's newly-minted 'big project' development agenda. The Bank was also beginning to see ASM in a very distinctive entrepreneurial light, going as far as calling for a different course of action, including the establishment of dedicated government-sponsored 'mining banks' to support activities:

Small-scale mining generally has very high technical and financial risks; funding the operations is hence difficult and expensive. The people operating much of the small-scale sector lack technical and managerial skills; any upgrading of the operations therefore must be accompanied by training...By its very nature, medium- and small-scale mining may need a significant technical assistance input to justify financial support...Hence, the mining bank will have to be organized and staffed to assist in project preparation and evaluation, to conduct in-depth project and company appraisals, to introduce new managerial and financial control systems, to supervise project implementation, and to provide the small mine with continuing technical assistance...Confusion arises over whether the bank is a source of finance for sector development or a channel for government subsidies to the small-scale mining operations. To assume the latter is wrong. A mining bank should be a financially viable entity with a well-qualified staff, autonomous both financially and managerially. Recipients of loans should be creditworthy 


\section{DRAFT (Paper Accepted for Publication)}

companies with technically and financially viable operations and projects. [Bosson and Varon, 1978, p. $160-161,264]$

No longer in sync with the donor 'mind-set' or the dynamics of the emerging mining and development agenda, host governments were left to self-finance the small-scale component on their own. Whilst Bank officials did highlight at the time the importance of 'planning for mineral sector development [which] must be coordinated with the development of other sectors in accordance with set priorities' (Bosson and Varon, 1978, p. 158), none of the proposals put forward in the 1970s and 1980s were very holistic in outlook. Rather than featuring under a broader rural development component, these ASM projects were fairly standalone and thus frequently abandoned once the first implementation problems began to surface.

The groundwork would be laid rather quickly for the 'technical, productivity-linked approach [to ASM]' that would emerge 'in the 1980s' (Jennings, 2003, p. 145). It marked the beginning of an extended and quite unproductive period for ASM support, during which a series of one-off projects were launched that further cemented the sector's peripheral position on the international development agenda.

\section{The 1980s}

In the 1980s, donor strategy experienced a major overhaul. Emphasizing 'big-project development' and 'economic liberalization', the World Bank and International Monetary Fund began to launch Structural Adjustment Programs (SAPs) in a number of developing countries heavily indebted to Western banks. In exchange for these loan packages, recipients were required to adhere rigidly to a series of conditionalities, including committing to reducing government spending and shedding labour in key public sector institutions; deregulating and privatizing their industries; and discontinuing subsidies and dismantling support services for domestic agriculture. Sub-Saharan Africa was the principal recipient of adjustment lending, receiving most of the packages awarded by the Bank and the International Monetary Fund before 1981. Lending intensified in the region in the 1980s and 1990s, by which time, 37 of its countries had implemented a combined 162 adjustment programs (22 countries are still engaged in such lending), a full 36 more than the number adopted elsewhere in the developing world over the same period. Overall adjustment lending in sub-Saharan Africa now exceeds US\$15 billion (Campbell 2001; Noorbakhsh and Paloni 2001), the changes it has ushered in helping to pave the way for export-based development. Backed by hundreds of millions of dollars in foreign investment, the region's large-scale mining sector and mineral exploration 'facility' would experience unprecedented growth during this period. The rapid expansion of industrial mining has long been viewed by the World Bank as a catalyst for resurrecting the deteriorated but resource-rich economies of sub-Saharan Africa. In countries such as Ghana, Tanzania, and Burkina Faso, a series of generous tax breaks were implemented, embodied within revised legislation, in an attempt to lure foreign investors (Campbell, 2003).

During the structural adjustment period, ASM continued to be viewed peripherally in development, despite exhibiting all of the attributes of a sector capable of nourishing growth and, inter alia, displaying jobcreation potential and rare ability to kick-start the development of downstream industries in impoverished settings. Ironically, Small-Scale Mining in the Developing Countries had highlighted many of these characteristics. But again, the actions taken by the United Nations and partners did little to bring these issues to the attention of other international donors and the NGO community: whilst the Bank was forging ahead with plans to overhaul Africa's large-scale mineral economy, the UN was still trying to define ASM for its own purposes. Two decades later, Jennings (2003) elaborated on the implications of this:

Until the link between small-scale mining and poverty was highlighted in the late-1990s, neither major donors nor governments showed much interest in assisting it. This gave little incentive for banks and other organs at the local level to participate. Moreover, the assistance that was provided by donors and development agencies tended to go to relatively few countries, and had mixed results. Small-scale mining was just not high enough on the agendas of governments and international donors to attract widespread, and sustained, attention. [p. 146]

Efforts to support the ASM sector, therefore, were undertaken outside of the main donor machinery - namely, the major development interventions being implemented under the auspices of SAPs.

The literature that began to emerge at this time conveyed as much, providing little more than periodic updates on the sector's production and composition. For example, Wels (1983) examined the main characteristics of the sector's production, including exploration techniques and the grade of ore operators typically target. Reflecting on what seemed to be the mind-set of the day, Alpan (1986) portrayed the sector in a very entrepreneurial light, arguing that 'in contrast with many other rural development schemes, small-scale miners generally are self-motivated and start their enterprise without government encouragement and assistance' (p. 95). Several scholars (e.g. Ali, 1986; Carman, 1987) voiced similar views but by far, the most significant sectoral analysis to emerge in the 1980s was Noetstaller's (1987) Small-Scale Mining: A Review of the Issues. 


\section{DRAFT (Paper Accepted for Publication)}

Perhaps not realizing at the time of writing how much influence he would have on the donor agenda, the author galvanized the policymaking community, cementing the view that ASM was exclusively about entrepreneurship. With so little recognition of the sector's livelihoods dimension from the outset, not surprisingly, a number of slightly disconnected and occasionally, rather erroneous, critiques emerged, and continued to do so well into the 1990s.

Governments and donors seemed genuinely confused about how to address ASM in policy. On the one hand, there was evidence of experts at the time believing that the sector indeed had unique attributes and therefore required separate regulatory frameworks and policies, a thinking perhaps best epitomized by Noestaller's (1994) "Small- vs. large-scale mining comparative profiles" (see Figure 2). On the other hand, there was very little effort being made to create a 'space' in policy for ASM. Failure to do so has spawned regulatory frameworks which do not adequately take into account the sector's particular nuances. Officers at the ILO would later reflect on the implications of this oversight, arguing that 'many projects to assist small-scale mining have failed or have not led to lasting improvements because they have treated small-scale mining as a subset of large, formal mining' (ILO, 1999, np). A survey carried out by Bugnosen et al. (1998) confirmed as much, concluding, from a sample of 26 developing countries, that 'the information available shows that smallscale mining legislation is usually introduced as part of the provisions of the general mining laws of a country'. The authors are referring to the outputs of moves made in the late-1980s and early-1990s to draft and implement ASM-specific regulations, particularly in sub-Saharan Africa. During this time, countries such as Ghana, Zimbabwe and Tanzania had instituted separate legislative frameworks for the industry. But whilst in these, and other, cases, ASM had certainly been 'given expression by provision for the grant of specific titles' as Kumar and Amaratunga (1994, p. 16) suggest, it continued to be treated very similarly to large-scale mining: as an industry populated by entrepreneurs.

Figure 2: Small-scale mining versus large-scale mining profile

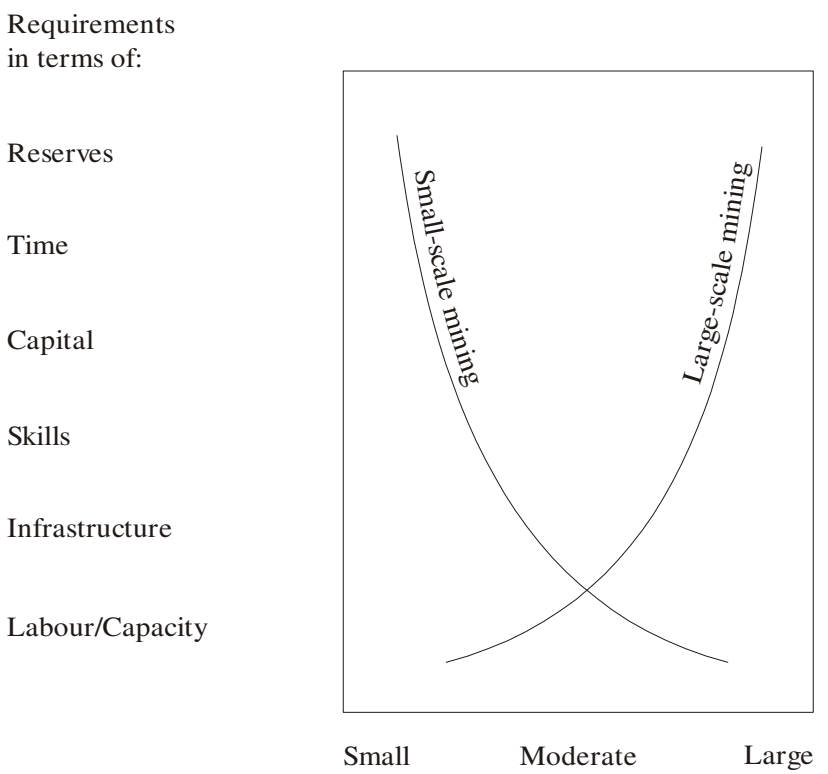

Source: Noetstaller, 1994

The laissez-faire approach employed to administer support to ASM operators in sub-Saharan Africa in particular mirrored the general approach being taken at the time to provide donor support. Parsons (1996) offered a condemning yet accurate description of a typical 'operationalized' top-down strategy, which seemed to have permeated everything developmental:

Traditionally, foreign 'experts' would play a role of 'all-knowing' authority. Expatriate engineers would sweep onto the scene, designing bridges and other large structures, having very little contact with local communities. Many of the engineer's projects would directly benefit the local elites or foreign companies, often intensifying disparities between the upper and low social and economic status...Such conditions still exist in the Third World, but it has become clear that this type of technical assistance does not raise development standards. [p. 170] 


\section{DRAFT (Paper Accepted for Publication)}

In the case of ASM, this 'top-down-ness' was particularly evident in several of the earliest sector-specific technological support projects launched, the majority proving, quite quickly, to be inappropriate for a large share of targeted groups. For example, a number of African countries, led by Ghana, began providing assaying services for ASM operators. As Davidson (1993) explains, here, funding provided by the World Bank and GTZ in the early-1990s was used to design and install a facility in the locality of Tarkwa. Plans were also hatched at this time to implement equipment leasing schemes and to construct a demonstration plant. But in Ghana - and in other African countries, such as Zimbabwe, where moves were also made to provide assaying services - it was quickly realized that most of the groups being targeted were comprised more of the 'dig and wash' and 'hit and miss' variety of miner, specifically individuals who were 'hand-to-mouth' with no knowledge of, or need for, such advanced analytical techniques. These services, therefore, would have likely only appealed to a small share of miners, if at all: namely, those in possession of a license, as informal, unregistered operators would have likely done everything possible to avoid contact with authorities over fears of potentially revealing their whereabouts.

The poorly-coordinated, top-down approach taken to administer technological support was also reflective in the planning stages of the 'centralized' ore processing facilities which began to surface across the region in the 1980s and 1990s. Led by Zimbabwe, with its flagship Shamva Mining Centre in the Northeastern part of the country, these service centres were intended as 'one stop shops' where miners could access a range of technical services, including assistance with processing their gold. But with little knowledge of target populations, including much of an idea about the demand for services and the number of people in need of assistance, the facilities at most of these centres became rapidly stressed, unable to cope with demand - as in the case of Shamva - or have simply been underutilized (Davidson 1993; Peak et al. 1998; Hilson et al. 2007).

These interventions were made when 'technical assistance' was the buzzword in donor circles and 'Integrated Rural Development' had become a centrepiece of African aid strategy. But whilst the ideas underpinning these efforts were certainly well calibrated with the thinking at the time, because the 'space' afforded to ASM in development policy remained quite small, there was little chance for the problems experienced with potentially-promising interventions such as Shamva to be corrected over time or for novel medium-to-long-term ideas such as providing assaying services to be critically 're-thought'. This was yet another missed opportunity for ASM because between 1973 and 1988, the World Bank had committed US\$19 billion to Integrated Rural Development Projects worldwide (Eicher, 2003).

Whilst upon reflection, it may seem to have made sense to include ASM - or push for its inclusion - in these largely-agricultural initiatives, with the thinking not extending to the sector, any suggestions to do so would have likely encountered significant resistance from policymakers. Even if the idea had been embraced, there would have been the added challenge of how to integrate it into policy. Towards the end of the 1980s, when aid had become significantly less project-focused and more programmatic, monies became tied more to SAPs than economic performance. Donors felt that some type of reform was in order, given that the loans administered in the 1960s and 1970s, including finances awarded for many Integrated Rural Development projects, 'dealt essentially with technicalities and avoided major political and cultural issues', a 'serious omission [which] deepened the governance and economic crises when they engulfed Africa' (Wamalwa, 1995, p. 14). With SAPs being linked to specific changes, such as the aforementioned trade liberalization, revaluation of currency and privatization, and calling for reform of certain industries, including agriculture and manufacturing, there was little capacity for absorbing ideas concerning other economic activities such as ASM. This is why calls for correcting problems associated with potentially-promising interventions, such as Shamva, or demands that the idea of providing assaying services be 're-thought' would not have attracted much policy attention.

In the absence of a robust, coordinated 'action plan' and adequate policy 'space' for ASM, a number of farfetched ideas were proposed. Hollaway (1991), for example, called for small-scale miners to be employed as 'pathfinders' for large companies, potentially 'kick-starting' and nourishing the development of industrial complexes. Time, however, would reveal how inappropriate this suggestion was, underscoring even further how little was known about the dynamics of ASM at the time. Throughout the 1990s, the sector's operations became populated with disgruntled skilled and semi-skilled mine workers made redundant under reform, during which scores of state-owned large-scale operations were privatized. Moreover, the idea of such a partnership did not mesh with the 'vision' outlined in the Bank's blueprint for mining sector reform in sub-Saharan Africa, A Strategy for African Mining (World Bank, 1992), which called for the development and support of two autonomous segments of the mining economy. Others tabled equally unrealistic ideas about technologies, most of which are far too sophisticated for target operators or have little chance of being adopted, given the level of mechanization in question. Examples include the texts Small-Scale Mining: A Guide to Appropriate Equipment (McDivitt, 1990), and Small-Scale Gold-Mining Processing Techniques in Developing Countries (Priester and Hentschel, 1992). Both prescribe a series of technologies - various loading techniques, cyanidation and crushing apparatuses - which millions of gold panners washing sediments along the banks of rivers across subSaharan Africa would have little use for in their rudimentary operations. 


\section{DRAFT (Paper Accepted for Publication)}

In summary, at a time when SAPs were catalyzing foreign investment in large-scale mineral exploration/extraction projects and stimulating a simultaneous 'land grabbing' by international mining houses in a region scarred by poverty, ASM was receiving comparatively little attention in policy. In the 1990s, however, the attitude toward ASM would begin to change, as governments and NGOs finally began to acknowledge that the sector did, indeed, have a livelihoods dimension which was being overlooked. But by this time, there was not much of a policy foundation to build on.

\section{The Early-1990s}

\section{Questionable Technical Assistance and More Missed Opportunities}

In the 1990s, there was a recognizable shift in support strategies for ASM, particularly in sub-Saharan Africa. The decade, however, featured two very distinct periods, each of which will be examined separately. The first, which spanned the beginning of the decade, was effectively an extension of the 1980s, during which, mainly technical-oriented interventions for ASM were pursued. But this was also a time when several bilateral agencies began to put aside monies to support, both directly and through various partnerships, ASM throughout the region. Although this assistance continued to be heavily disconnected, ideologically, from the donor programs launched and development initiatives undertaken at the time, it was very focused and with the right backing, could have had profound impacts on ASM groups. It was not until the late-1990s, however, that the donor support being provided for ASM in the region began to feature a recognizable livelihoods dimension.

The 1980s will always be remembered, in ASM circles, as a decade in which significant technical support was provided to operators, particularly in sub-Saharan Africa. Most of the interventions made would fail to have a lasting impact, targeting, once again, a group of people designers believed were rogue entrepreneurs. Little had changed by the early-1990s: the bulk of sectoral support remained technical in its orientation, focusing mainly on improving the efficiency of operations themselves. More comprehensive technical assessments of ASM did, however, begin to emerge at this time - a significant departure from the series of largely-nondescript essays and biased reports produced on the subject during the 1980s. Key among these was Priester et al.'s (1992) analysis of gold processing technology and Hollaway's (1993) survey of different small-scale mining equipment. The latter is particularly insightful, as it highlights the potential barriers preventing ASM operators, particularly in sub-Saharan Africa, from adopting more efficient equipment. It also identifies various apparatuses the region's miners should avoid, given the high cost and the level of technical expertise required for their effective operation.

By the early-1990s, the German Technical Cooperation (GTZ) had quickly become the 'face' of bilateral aid for ASM - at least in sub-Saharan Africa. The organization was actively involved in significant project work in Zimbabwe and Ghana, two countries with lengthy and very dynamic artisanal gold mining histories. It was a time marked by 'the rise in importance of NGOs', which would 'become if not major then at least significant actors on the aid scene' (Riddell, 1992, p. 65). Plans hatched by GTZ for delivering technical support to ASM in both countries, therefore, had rapidly come to fruition because the organization had successfully forged partnerships with civil society. In Ghana, GTZ monies were used to help finance the Small Scale Mining Project (SSMP), under which a series of local ASM administrative centres were established in areas of the country where activity was most heavily concentrated. One significant move made with GTZ monies was the installation, at its flagship small-scale mining district centre in Tarkwa, of the aforementioned assaying facility and an accompanying technological demonstration centre (Hilson, 2002a).

In Zimbabwe, GTZ partnered with the UK-based Intermediate Technology Development Group (ITDG) and supplied most of the financing for the $£ 450,000$ Shamva Mining Centre. Constructed in 1991, Shamva was, as indicated, intended as a 'one-stop-shop' for ASM, providing processing services and technical advice to operators. One of its main objectives was to reduce mercury emissions from local gold mining activities, which was accomplished by constructing a ball mill or centralized processing facility and 'installing' a number of mercury retorts. The latter was achieved by first studying the available models at the time, and subsequently implementing the most appropriate design. ${ }^{2}$ Following this, management produced a four-page pamphlet, in which the benefits of using a retort were detailed and step-by-step instructions provided that showed how to fabricate the device using basic materials. The leaflet was produced in English, Portuguese and Spanish; later translated into Bahasa and Swahili; and dispatched to the offices of NGOs and local government in 27 countries (Davidson 1993; Mugova 2001).

In most cases, such interventions, whilst promising, have been short-lived, largely due to the design of the technologies implemented. During the initial design phases, some effort is typically made by donors and

\footnotetext{
${ }^{2}$ A retort is an enclosed device, typically fabricated from metal, in which mercury amalgam is heated. It reduces emissions of mercury considerably by 'trapping' fumes, a large percentage of which condense, and can be collected and reused.
} 


\section{DRAFT (Paper Accepted for Publication)}

partner NGOs to study existing equipment and use this analysis to assist with implementation. With the passage of time, however, more often than not, it has been revealed that the data gathered were insufficient to make informed decisions on model types. In Zimbabwe, it was a case of designers failing to adequately anticipate demand for Shamva's services with the baseline surveys undertaken. The Centre had initially been designed to support 200 miners. But when it emerged that the milling services it was providing led to income increases of as much as 30 percent in certain cases and that the fees paid to miners for processed ore were linked to the final price at which gold was bought by the Reserve Bank, demand soon outstripped supply, resulting in many more miners patronizing Shamva's services. By the early-1990s, it became evident that the capacity of the ball mill, which could only produce one tonne ore/hour, was incapable of satisfying demand, forcing many miners to wait between three and six weeks to have their ore processed; unable to wait, most returned to the riverside, where they resumed environmentally-destructive panning activities. These production problems were solely due to miscalculations made during the design phase, and could have been avoided altogether had initial baseline censuses been carried out (Mugova, 2001).

In Ghana, it was simply a case of providing an inappropriate service. Like Shamva, its ineffectiveness was a direct result of policymakers and donors failing to collect the requisite baseline data - specifically, detailed ethnographic information. These data would have shown that, the group of miners being targeted were not entrepreneurs as was believed but rather individuals crippled by hardship who were trying to sustain their livelihoods. The assaying lab, which is more suitable for a medium-scale mining sector populated by skilled professionals (a group that had not yet emerged in Ghana by this time), was, not surprisingly, underutilized. The blunders continued, the biggest debacle being the hiring of the Central Regional Development Commission (CEDECOM) to help deliver financial and technical assistance to small-scale gold miners. The Ghanaian Government and GTZ requested for CEDECOM to make recommendations for equipment leasing schemes, ideas which would prove inappropriate, largely because the organisation had, up until that point, never worked with small-scale miners before, and therefore relied heavily on information drawn heavily the experiences of its staff assisting small-scale fisheries. The government eventually abandoned the scheme, and was forced to sell all equipment it had purchased for lease at discounted prices (Hilson, 2002a, 2002b).

Once derailed, these projects had little hope of getting back on track because, as indicated, ASM was not being given much attention in regional development strategy. As explained by Jennings (1994) at the time, 'There are, regrettably, few examples of specific policies for small-scale mining that cover its development and operation' (p. 11).

\section{Formalization of Small-Scale Gold Mining in sub-Saharan Africa}

Towards the late-1980s, it had become apparent that SAPs were not facilitating development in subSaharan Africa as predicted. A wave of studies (e.g. Cornia et al., 1987; Nicholas, 1988; Mosley and Smith, 1989; Anyinam, 1989) emerged which showed that liberalized trade, privatization and a diminished responsibility of the state had catalyzed very little local economic development. The gulf between the rich and poor was broadening, and in many cases, the latter's situation had worsened considerably. Moreover, and as confirmed by Eicher (2003) in a review of unpublished and published works, there was a sharp division in opinion between academics and donors at the time on which poverty alleviation strategies would best serve the region's needs.

But despite these rather worrying signs, the World Bank and IMF continued to press ahead, maintaining their course in sub-Saharan Africa. The former published two reports which justified further its aid strategy - in the process, perpetuated adjustment lending - in the region. The first, Sub-Saharan Africa, From Crisis to Sustainable Growth: A Long Term Perspective Study (World Bank, 1989), sought to deflect initial criticisms of adjustment and to further rationalize structural adjustment. Then-Bank President Barber Conable states, in the preface, that 'adjustment efforts must be continued and the reforms broadened and deepened' ( $p$. xi). The report itself claims 'that a general recovery had begun in sub-Saharan [Africa] to a great extent resulting from the policy reforms implemented under the umbrella of Bank-funded structural adjustment programs' (p, 1459). The second report, Adjustment in Africa (Husain and Faruqee, 1994), though slightly less bold in its forecasts and calls, was equally complimentary of the adjustment experience in sub-Saharan Africa, maintaining that 'in the macroeconomic, trade, and agricultural sectors, the major task is to move forward with the current approach to policy reform'. It furthermore outlines 'the role that adjustment needs to play in improving the policy environment for the provision of basic social services and protecting the environment' ( $\mathrm{p}$. $\mathrm{xxi})$.

Upon reflection, perhaps the decision to stick with the status quo was a deliberate strategy employed by donors in an attempt to buy time whilst brainstorming a new donor strategy for sub-Saharan Africa. The early1990s were indeed an opportune time for the Bank and partners to 'rethink' their approach to the region's development: it was not only a period when 'poverty alleviation' once again became the focal point of the global aid agenda but also when, as Eicher (2003, p. 20) explains, donors were open to 'letting the flowers 


\section{DRAFT (Paper Accepted for Publication)}

bloom' - specifically, 'add[ing] new activities while cutting aid to implement them'. The decision to 'add but cut' financial resources could be viewed as direct action taken by an increasing number of donors at the time in response to rhetoric about the need for 'good governance' in lending, particularly within the bureaucracies of countries being targeted for aid. The ASM sector, however, was not one of the 'new activities' seen to have potential to contribute to economic development in sub-Saharan Africa. This oversight was somewhat ironic: being an industry which, as will be explained, donors helped to 'create' and shape that was not seen to be a viable enough activity to justify its inclusion in a broadened aid agenda with poverty alleviation at its core. Failure to recognize, at a time when donor policy was in transition, both the economic importance and povertyalleviation potential of ASM, has proved catastrophic, particularly for sub-Saharan Africa.

By the early-1990s, many more African countries, in the spirit of structural adjustment, had opened up their mineral economies to foreign investment. Bank officials would present a case for liberalizing large-scale mining in the landmark report, A Strategy for African Mining (World Bank, 1992), calling on African governments to transition toward an export-based large-scale mining sector populated by foreign multinationals. A main issue highlighted in the document is the 'Ghana miracle' of gold production, despite caution raised at the time about it being 'unlikely to be generalised to other countries in Africa given the specificity of Ghana's history of mining investments' (Chachage, 1993, p. 97). Bank officials would nevertheless argue that the meteoric boom in large-scale gold mining in the country was the result of its 'enabling policy environment', a situation which, they further contested, was brought about by its new-found ability to attract foreign investment, and managerial and technical expertise. It was implied throughout the text that sweeping reforms made this possible, facilitating the sharp rise in gold production (from 277,000 oz in 1983, to 400,000 oz in 1989, and subsequently, 1,200,000 oz in 1993) experienced in the country in the 1980s and early-1990s (Chachage, 1995). A number of other African countries, including Tanzania, Mali, the DR Congo, Mozambique and Uganda, have since followed Ghana's lead, implementing equally-sweeping reforms in an attempt to attract foreign interests to develop their large-scale gold exploration and mining economies. But as will be explained, many of these changes were made at the expense of ASM, consequently impeding its establishment and growth in the formal economy of sub-Saharan Africa.

Most of the press coverage of ASM, particularly in sub-Saharan Africa, focuses on the industry's many 'ills', including its supposed child labour problem, the prostitution and HIV/AIDS widespread in the communities where minerals are extracted, and the environmental footprint of activities. At the same time, very little attention is paid to understanding how these problems have come about, or why the industry itself is in the state it is and its operators struggle to mechanize and gain a foothold in the formal economy. Significantly, and as pointed out earlier, the donor strategy which prevailed in the 1980s and 1990s played a heavy hand in shaping and fuelling the rapid growth of the ASM sector - particularly gold extraction and panning - found across subSaharan Africa today, and what policymakers have come to identify it as: a labour-intensive, largely-informal, chaotic economy, comprised of low-tech operations and populated by rogue entrepreneurs.

There are two aspects to consider here. First, whilst there is little disputing that, by implementing SAPs and sweeping reforms, host African governments have created an 'enabling policy environment' for largescale gold mining, they have, at the same time, created the ideal policy conditions for the growth of illegal ASM activity. By the end of 1995, 36 African countries had implemented rigid policy frameworks and legislation with the aim of legalizing the industry-a move described by Chachage (1995, p. 47) as the 'officialization of hitherto illicit activities' - and/or had established sector-specific administrative and technical institutions to facilitate this, or were in the process of doing so (Fisher, 2007). But the hasty enactment of licensing systems, often with very little consideration for the people being targeted, suddenly made 'unregistered' artisanal and small-scale miners 'illegal'. This was portrayed as a problem for African countries in A Strategy for African Mining (World Bank, 1992), likely because of the perceived inconvenience tens of thousands of artisanal operators would present to a government opening up its mineral economy and demarcating large parcels of land to foreign multinationals. To this end, the document rather baselessly claimed that 'Many artisanal miners are individuals or families who typically have no mining rights, no mine plans, and sell their product to whoever turns up to buy it' (p. 42).

Toward the late-1990s, it had become apparent that, across sub-Saharan Africa, superimposed ASM regulations were impeding the formalization of activities, rather than encouraging individuals to obtain licenses and legitimize their operations in the eyes of the law. Officers at the ILO were among the first to reflect on why, pointing out in the landmark text, Social and Labour Issues in Small-Scale Mining (ILO, 1999) that:

Small-scale mining is bedevilled with too many regulations that are mostly designed to constrain it and too few inspectors to ensure that they do. There is therefore little incentive for small-scale mines to conform, particularly if the risks of being caught and of sanctions being applied are minimal. If smallscale mining is to be encouraged to operate legally, legislation must be (at least) even-handed in allowing small-scale miners access to suitable land for prospecting and mining activities. It must be "user friendly" 


\section{DRAFT (Paper Accepted for Publication)}

as far as the issuing of permits and the granting of licences are concerned - permits that provide clear security of tenure for a reasonable period so that small-scale mining can become established. [np]

Davidson (1993) was one of very few individuals who had the foresight, during the heyday of structural adjustment, to emphasize the importance of providing adequate 'space' in policy for ASM formalization in countries which have implemented reforms. To achieve this, the author argued, 'Governments must be prepared to move beyond the establishment of legal frameworks, to identify deposits and areas amenable to small-scale development, including the preliminary evaluation of their technical and economic viability at different levels of operation' (p. 317). The mining legislation and policies implemented under reform across sub-Saharan Africa, however, were not 'even-handed'; nor did donors acknowledge at the time the importance of creating policy environments in which both international mining houses and licensed indigenous small-scale operators could flourish undeterred. Rather, the only point of emphasis seemed to be catering to the former, a bias reflected in A Strategy for African Mining, which, inexplicably, called for reformed mining agendas in subSaharan Africa to treat large-scale mining and ASM equally, despite the two being very different in composition:

Much of the mining legislation enacted in African countries since independence envisages that 'smallscale mining' will be reserved for citizens or local companies while 'large-scale mining' will be the province of state mining corporations or large foreign mining companies...There is no good reason to create differential access to mineral rights for different classes of mining investor. A state mining enterprise should compete on the same terms as a privately-owned company, foreign on the same terms as national, large companies under the same broad rules as small ones. [p. 22]

Throughout sub-Saharan Africa, reforms, manifested as overhauled investment codes and legislation, would both insulate and incubate large-scale mining activity, which would experience unprecedented growth over the course of the decade but rather problematically, taking the form of resource 'enclaves' disconnected from wider society (see Ferguson, 2005; Ackah-Baidoo, 2012). Formalized ASM activity, however, would grow at a comparatively pedestrian rate, its operators struggling to mobilize the funds needed to secure the requisite permits and viable plots in mineralized landscapes, large sections of which had been already been demarcated to foreign multinationals.

As stated in A Strategy for African Mining, 'the original colonial mining laws defined an "open" system which anyone who had reached the age of majority, and was of sound mind, could acquire a statutory right to prospect and mine'. This legislation, it further maintained, 'was drawn up with the small-scale gold rush type operation then prevalent in mind and envisaged a negligible economic or technical role for government [and]...provided insufficient rights and obligations for both governments and investors, including inadequate security of tenure for investors willing to undertake the larger mining operations which gradually became important in Africa' (p. 21). Today, the opposite is true: a significant share of the revised legislation now in place in sub-Saharan Africa was drawn up with the large-scale, mechanized, foreign-financed operation in mind and provides insufficient rights and obligations for indigenous small-scale miners. These legislative and policy frameworks have discouraged formalization and fuelled the growth of the illegal ASM activities found scattered across the region today.

\section{Structural Adjustment and the Growth of Informal Gold Mining in Sub-Saharan Africa}

Structural adjustment has certainly fuelled the rapid growth of ASM across rural sub-Saharan Africa, although not in the way perhaps anticipated by proponents of A Strategy for African Mining. Rather than facilitating formalization, reforms have catalyzed the expansion of the region's informal gold mining economy, to which, over the past two decades, tens of thousands of people made redundant under structural adjustment have congregated in search of employment.

This crucial link, however, would not be acknowledged by donors and policymakers for several years. Officers at the ILO were the first to make the general observation in the landmark report, Social and Labour Issues in Small-Scale Mining (ILO, 1999). It states that 'The impact of structural adjustment programmes, low commodity prices or drought on private and public sector employment, trading, farming and inflation has led many people, especially women who relied on subsistence agriculture, to seek new, alternative additional paid employment for a better quality of life, or more usually, just to survive' (np). Officials at the United Nations Commission for Africa (UNECA) echoed these sentiments:

Increasing numbers of people have turned to SSM [small-scale mining] to seek alternative livelihoods. In many cases, this was impelled by growing economic crises, the effects of structural adjustment, particularly in sub-Saharan Africa, which increased unemployment, mine redundancies in large mine 


\section{DRAFT (Paper Accepted for Publication)}

companies due to crumbling mineral prices, and decreasing rural livelihood choices, chiefly in areas affected by natural (mainly droughts and floods) and man-made disasters. [UNECA, 2003, p. 2]

Significantly, ASM scholars (e.g. Davidson, 1993; Labonne, 1993, 1996; Noetstaller 1994), the vast majority of whom seemed preoccupied with the issue of formalization, also seemed to overlook how SAPs were fuelling the growth of informal gold mining activity, particularly in sub-Saharan Africa.

In recent years, however, the link has been made, and quite explicitly. Banchirigah (2006), for example, pulled together several illustrative but isolated examples from previous research which suggested that many of those made redundant followed SAP implementation in sub-Saharan Africa were, indeed, finding homes in the informal gold mining economy. Among the more informative works cited were those of Dreschler (2001), who reflects on the situations in Zimbabwe and Tanzania specifically. In the case of the former, it was pointed out that following implementation of the SAP in 1990, 'thousands of workers lost their jobs... and many of the retrenched turned to artisanal gold mining'. The author reported much of the same in the latter, arguing that 'the importance of small-scale and artisanal mining in Tanzania is reflected by the fact that: it offers attractive employment to many people particularly from the rural community; and it resettles those who have lost their jobs in the cities due to the newly adopted structural adjustment programme' (p. 140). Similar phenomena have been observed in Ghana, where, as Hilson and Potter (2005) report, scores of skilled and educated people made redundant during a protracted period of structural adjustment, including various largescale mine personnel, accountants, bookkeepers, teachers and public sector workers, have turned to informal gold mining for their income.

Reinforcing the policy and donor position at the time, Mohan (2000, p. 107-108) attributed such labour movements to 'the lure of quick wealth', which, the author argues, leads 'young men [to] tak[e] up [artisanal] mining instead of farming'. As explained earlier in this paper, however, recent research has shown that for hundreds of thousands of rural African families, this movement is not a choice motivated by ambition; it is rather more reminiscent of a survival strategy, given the diminished viability of farming - long their main source of income - in a liberalized agricultural market. There were certainly scattered reports throughout the 1980s and early-1990s of livelihood diversification taking place. On a general note, Weis (1983) pointed out how 'They [small-scale miners] provide employment, full-time or seasonal, in depressed agricultural areas, and reduce the drift to towns' (p. A19). One of the more illustrative accounts was provided by Chachage (1995) about Geita, which continues to be one of Tanzania's richest gold mining districts, in the early-1990s. The author reported that 'what is interesting is that many of the villagers who are investing in food agriculture have done so on the basis of profits from gold' (p. 90). There were certainly indications early on of there being a range of motivations behind people's participation in informal gold mining - drivers which have since been broadly grouped as pull factors or the aforementioned lure of quick wealth, and push factors or principally poverty or hardship (Hilson, 2009). Donors and policymakers, however, failed to pick up on these two very distinct narratives and more broadly, recognize what research conducted over the past decade has revealed: that the informal gold mining communities found across rural sub-Saharan Africa are comprised of a heterogeneous mixture of people.

Interestingly, today, ASM and farming are interconnected as people's livelihood strategies have become increasingly more complex and dynamic. Though not a newly observed relationship (Binns, 1982), in response to increasing economic difficulties and, most recently, rapidly rising mineral prices, the positive link between the two sectors has been maintained and cemented. Indeed, even in spite of the severe dislocating effects of war, as shown by Maconachie and Binns (2007) in a longitudinal study of miners and farmers in Sierra Leone, the symbiotic dovetailing and circulation of labour between the sectors is an integral part of rural livelihood strategies. The seasonality of both farming and mining results in mining being undertaken during the dry season, when rivers are low, and farming dominating the rainy season. Furthermore, smallholder farmers are able to sell surplus produce at higher prices to mining areas, and, itinerant traders who buy from the farm gate and deliver to the mining areas also reap the benefits from increased prices and trade. Farmers are also able to invest and develop their farms from increased economic returns (Maconachie and Binns, 2007; Maconachie, 2011). As a result, complex and enduring trading and social networks have developed around this more resilient, capital-strong, intertwined livelihood strategy of farming and mining.

Implemented by individuals who believed that small-scale gold mining was populated mainly by rogue entrepreneurs, the industry support packages which did surface up until the early-1990s failed to take stock of these dynamics. Most - at least in sub-Saharan Africa - were highly-technical in orientation; and, as little emphasis was placed on studying local cultures beforehand and using this analysis to inform the design of assistance schemes, not surprisingly, most interventions failed to have a lasting impact. Perhaps most significantly, sectoral support schemes only targeted licensed operators which, as the next section of the paper illustrates, explains why, despite a marked change in perception toward ASM, so few Africans would benefit 


\section{DRAFT (Paper Accepted for Publication)}

from the multimillion dollar industry assistance schemes that would emerge over the course of the next two decades.

\section{The mid-1990s Onward: Perpetuating a Disconnected Policy Dialogue?}

The 1990s is often seen as a turning point for ASM policy. As the impacts of structural adjustment began to take effect, and joblessness became widespread, perspectives on ASM began to change, particularly in the donor community. The first significant signs of this took place at the international workshop, the Harare Guidelines for the Development of Small/Medium-Scale Mining, held in Harare, Zimbabwe, February 1993 (see ILO, 1999). Organized by the United Nations Department of Economic and Social Affairs, and held more than two decades after publication of Small-Scale Mining in the Developing Countries, the workshop brought together experts to discuss in depth, for the first time in an international setting, the various aspects of ASM, specifically, its legal, financial, commercial, environmental and social, and technical attributes (ILO, 1999). Its aim was to share knowledge of best practices and facilitate the formalization of hitherto unlicensed activities. Importantly, the Harare Guidelines was the first ASM seminar which did not focus exclusively on definitions, legality and production, although, inevitably, discussions did, at times, gravitate toward these issues.

Moreover, the seminar - rather strangely - was built around promoting Zimbabwe as a successful model for profitable ASM activity. It seemed that the decision to host the event in Harare was based largely on the country having in place what was believed by many at the time to be the requisite support structures and legal and operator-friendly policy framework to catalyze profitable activity. Of course, attendees, the vast majority of whom were industry specialists, consultants and government officers, seemed oblivious to the shortcomings of the soon-to-be-overrun Shamva Centre, and failed to anticipate the inability or reluctance of Zimbabwe's Rural District Councils to enforce the Mining (Alluvial Gold) (Public Streams) Regulations, 1991, hailed at the time as landmark legislation for the sector (Maponga and Ngorima, 2003). Moreover, as one expert relayed in a personal communication, 'after the meeting we felt that a lot of precious time and energy had been lost with the size issue' (Expert 1, 2013). Most delegates continued to ignore ASM's poverty dimension, which, ironically, needed to be embraced in order to transform the sector into 'a profitable mining activity based principally on the successful Zimbabwe model', an ambition shared by many of the seminar's attendees.

Despite being dominated by such discussion, the meeting in Harare did generate enough dialogue about ASM's social attributes to warrant a themed international meeting on the sector's livelihood and poverty aspects. In May 1995, such a seminar finally took place at World Bank headquarters in Washington DC. The landmark event, The International Roundtable on Informal Mining, featured the same delegates but significantly, the dialogue had changed. One expert ${ }^{3}$ reflected on the objectives of the Roundtable during a personal communication:

The usual suspects were attending the meeting. We were concerned by the lack of breakthroughs due inter alia to the transient nature of ASM (artisanal came to replace small!) and the increase of informal/illegal/artisanal mining-gold rush type poverty-driven and opportunity driven. The poverty link became obvious to most players although some believed that entrepreneurship existed in some mining areas and that full legal rights should be granted: Land rights (claims) which could be transferable to allow for upgrading. Claims could be used as collateral for loans...Providing good practices for mining co-operatives was regarded as a critical-mass-building solution (towards economy of scale). What changed after that? Need to launch cross-sectoral initiatives (environmental, social, women issues), integrated rural development, even if many miners had a get-rich-quick mentality (usually foreigners). Many subsistence farmers/peasants mine during the dry season when they were idle. This was regarded as an ideal set up to be strengthened. Unfortunately its was rarely the case. Social workers complained that mining was disrupting their programs and making results aleatory. Hence the need to work with them to develop holistic development approaches.

The reference made by the expert here to 'poverty-driven' requires further explanation. It was at the Roundtable where the growth of ASM was associated with hardship for the first time in an international gathering. Delegates seemed to be in general agreement that, 'to a large extent, informal mining is a poverty-driven activity' (Barry, 1996, p. 1). There was also discussion about some operators potentially being trapped in a vicious cycle of poverty similar to that outlined earlier, fuelled by, inter alia, inadequate capital investment, limited access to quality equipment and poor productivity. The reference made to 'integrated development projects' and allusion to rural dwellers' seasonality signify the change in policy thinking brewing at the time: namely that ASM was not just a standalone business enterprise but rather an economic activity central to the

\footnotetext{
${ }^{3}$ Personal communication, international expert (Expert 1, 2013).
} 


\section{DRAFT (Paper Accepted for Publication)}

livelihoods of diversified rural households, many with farming at their core; and, which - at least in the case of sub-Saharan Africa - had become increasingly important during trying economic times.

This new 'thinking' was certainly reflected in the donor rhetoric during the years following the Roundtable. By the late-1990s, there was - at least so it seemed - a marked and radical change in donor philosophy, a time when 'livelihoods' became a point of emphasis. Pioneering work carried out by the NGOs CARE International, OXFAM and the International Institute for Environment and Development, and subsequent analysis undertaken by the UNDP and UK Department for International Development, led to the establishment of the landmark Sustainable Livelihoods Framework (SLA). Importantly, when applied to ASM, it drew attention to the imperativeness of fully understanding the inherent diversity and complexity of livelihood strategies and risk aversion and thus clarified the interconnectedness of mining in many livelihood portfolios. It is beyond the scope of this paper to provide an exhaustive analysis of the SLA but its emergence certainly reflected the shift in thinking towards a more people-centred approach to international development. Part of its attraction was that it captured and synthesized diverse ideas; conceptually, drew on changing views of poverty, recognizing the different challenges facing communities and the institutional structures which affect them; and made people - rather than resources, organizations or facilities - the focus of action and concern, emphasizing participatory action (Solesbury, 2003).

Discussion on sustainable livelihoods eventually turned to ASM, initiated by forward-thinking practitioners at the United Nations Department for Economic and Social Affairs (DESA). In 2000, DESA launched the US\$280,000 'Poverty Eradication and Sustainable Livelihood: Focusing on Artisanal Mining Communities' project. Centring on the country case studies of Ethiopia, Ghana, Guinea and Mali, the project sought to 'produce a set of policy options and best practices, for use by government, IGOs [International Government Organizations] and Civil Society at the micro, meso and macro levels, that contribute towards poverty eradication through: a) promoting opportunities of developing alternative and complementarily sustainable livelihoods for those engaged in artisanal mining; and b) upgrading the artisanal mining sector to an economically viable activity'. ${ }^{4}$ Towards the end of the project, a workshop was held in Yaoundé, Cameroon to share findings and mobilize additional funding. The main output of the workshop was the 'Yaoundé Vision Statement', an ambitious call to 'contribute to sustainably reduce poverty and improve livelihood[s] in African Artisanal and Small-scale Mining (ASM) communities by the year 2015 in line with the Millennium Development Goals' (UNDESA, 2003, p. 6-7). An expert reflected on the project aims in greater depth during a personal communication:

In 2000, we thought (I thought to be more accurate) that SLA could bring a breakthrough as institutional support for ASM had bogged down. On the one hand: few technical projects, and on the other: endless technical meetings making the same old recommendations that were too unrealistic to be implemented. The discussions were becoming 'incestuous' so to speak as these meetings were attended by the same group of people whose thinking lacked flexibility. Moreover, in their majority technical projects were not sustainable; their achievements were short-lived because no income was generated to keep the project going after funding stopped. If no income could be generated it proves that the sector was not economical. Many mining colleagues refused to face the truth. I wanted to bring something fresh, multisectoral approach to the debate. As you know it is hard to break sectoral barriers, be in government or institutions like the World Bank, UN, DFID etc...ASM has so many facets and dimensions that it cannot be addressed by the sole mining dept. Rural (subsistence agriculture) was affected by shock and stresses and to cope many farmers resort to dig for minerals: alternative source of income. [Expert 1,2013]

One of the more significant issues broached by delegates in Yaoundé was ASM's conspicuous absence from the region's freshly-drafted Poverty Reduction Strategy Papers (PRSPs), a collection of documents produced by the World Bank and IMF in the late-1990s, with inputs from host governments, as replacements for SAPs. The PRSP is intended as a framework for countries approaching these institutions for loans to follow: in theory, a detailed document, developed with inputs from communities and civil society, which identifies key priorities in the areas of poverty alleviation and local economic development (after Khan, 2010). The report produced following the Yaoundé seminar makes several significant points regarding ASM's oversight in the PRSP project in sub-Saharan Africa, including how, 'Not surprisingly, very few Poverty Reduction Strategy Papers (PRSPs) make reference to ASM'; that 'Mining authorities should revisit their contribution and commitment to poverty reduction... [which] should go beyond the provision of increased fiscal revenues, foreign exchange earnings, and mining jobs - the recognized tenets of the trickle-down economic model'; and how the 'mainstreaming of ASM into the PRSP process also implies poverty reduction benchmarking within mining policies' (UNDESA, 2003, p. 2). Buoyed by momentum generated by ILO officers, who again, in the late 1990s, began calling for ASM's

\footnotetext{
4 'Poverty eradication and sustainable livelihood: focusing on artisanal mining communities' http://esa.un.org/techcoop/flagship.asp?Code=RAF99023 (Accessed 24 November 2013).
} 


\section{DRAFT (Paper Accepted for Publication)}

empowerment (ILO, 1999), the efforts made by DESA officials to stimulate a critical 'rethink' about the sector's inclusion in PRSPs were timely.

By this time, several organizations had developed their own, more dynamic, definitions of ASM, and continue to do so, a sign of the sector's growing global recognition (See Table 2). Moreover, and whether a coincidence or not, many of the PRSPs implemented shortly after Yaoundé did seem to portray ASM in a different light. For example, Ghana's first PRSP, An Agenda for Growth and Prosperity (IMF, 2003) reinforced points raised by ILO officers (ILO, 1999), arguing that 'Current mining laws tend to disproportionately favour large-scale mining enterprises' and that in order 'To address this apparent imbalance, measures will be put in place to expand the scope and increase the support to the small and medium scale sub-sector with the view to making it the predominant means of exploiting minerals in the long term' (p. 91). Similarly, Tanzania's second PRSP, National Strategy for Growth and Reduction of Poverty (IMF, 2005), stresses how 'There is need to balance the livelihood requirement of artisanal miners with the economic objectives of the large-scale operators' (p. 7).

But the discussion failed to generate meaningful action over the medium-term. Moreover, what seemed, at first, to be a dynamic dialogue about ASM, would rapidly fizzle. In the case of Ghana, the expectation was that the ideas tabled about ASM in An Agenda for Growth and Prosperity would be further developed in the country's second PRSP (IMF, 2006), Growth and Poverty Reduction Strategy (GPRS II) (2006 - 2009) but the document fails to even mention the sector. It rather reverts to core themes broached in $A$ Strategy for African Mining (World Bank, 1992), stating, inter alia, that 'Growth in the mining sub-sector [of Ghana], particularly gold, was largely due to substantial infusion of capital from both local and external sources aided by the stable environment created by the institution of policies that have insulated earnings and costs from foreign exchange controls' (p. 15-16). The subsequent PRSP implemented in Tanzania, National Strategy for Growth and Reduction of Poverty II (IMF, 2011), also abandons ASM and, in the spirit of A Strategy for African Mining, portrays large-scale activity as a catalyst for 'kick-starting' local economic development. It states that, 'The mineral sector has a great potential to contribute to GDP if sustainably exploited and efficiently managed' furthermore stressing that 'The vast mineral deposits in the country point to a high potential of the sector's contribution to growth and socioeconomic transformation' (p. 49). Overall, the rhetoric espoused and efforts made by DESA, the ILO and a small group of NGOs proved insufficient in creating up a 'space' for ASM in a complex body of donor policy machinery which, for decades, had excluded and at times marginalized the sector. Whilst certainly doing an excellent job of mimicking the language of the donor agenda at the time, embracing themes such as 'livelihoods', 'pro-poor strategy' and 'integrated rural development', projects and policies for ASM - at least in the case of sub-Saharan Africa - remained standalone, launched outside of national and regional-level support strategies.

Table 2: Selected Definitions of Artisanal and Small-Scale Mining

\begin{tabular}{|c|c|}
\hline ASM Definition & Organization \\
\hline $\begin{array}{l}\text { 'Definitions... are disputed...but broadly speaking, ASM operations exploit marginal or } \\
\text { small deposits, lack capital, are labour intensive, have poor access to markets and } \\
\text { support services, low standards of health and safety and have a significant impact on } \\
\text { the environment'. (Buxton, 2013) }\end{array}$ & $\begin{array}{l}\text { International Institute for Environment and } \\
\text { Development. }\end{array}$ \\
\hline $\begin{array}{l}\text { '...largely a poverty driven activity, typically practiced in the poorest and most remote } \\
\text { rural areas of a country by a largely itinerant, poorly educated populace with little } \\
\text { other employment alternatives'. (World Bank, 2013) }\end{array}$ & The World Bank \\
\hline $\begin{array}{l}\text { 'An artisanal and small-scale miner is self employed, but can also be an employee, } \\
\text { working as an individual or in a family unit linked to a local community, mining } \\
\text { group, co-operative, or ASM organisation. Those involved are usually poor, vulnerable } \\
\text { men, women and children driven to artisanal mining for survival...[new miners } \\
\text { entering the sector] scavenge for a time'. (Malder, 2011). }\end{array}$ & $\begin{array}{l}\text { Fairtrade Foundation and Alliance for } \\
\text { Responsible Mining }\end{array}$ \\
\hline $\begin{array}{l}\text { 'There is no formal definition for ASM, but it is broadly understood to refer to mining } \\
\text { activities that are labour-intensive and capital-, mechanization- and technology-poor'. } \\
\text { (ICMM, 2010) }\end{array}$ & $\begin{array}{l}\text { International Council on Mining and Metals } \\
\text { (ICMM) }\end{array}$ \\
\hline $\begin{array}{l}\text { 'There is no consensus on what constitutes a small-scale mining operation; neither is } \\
\text { the boundary between ASM operations clearly defined. This is partly because } \\
\text { definitions vary by country. Despite differences in definition, common attributes stand } \\
\text { out: most miners are seriously under-capitalized, rarely operate as proper business } \\
\text { enterprises and lack appropriate and modern technology'. (UNECA, 2011) }\end{array}$ & $\begin{array}{l}\text { United Nations Economic Commission for Africa } \\
\text { (UNECA) }\end{array}$ \\
\hline $\begin{array}{l}\text { '... [ASM] commonly represents a spectrum of activities ranging in scale from small to } \\
\text { large that is generally distinguished from 'formal' mining by a relatively low degree of } \\
\text { mechanization, high degree of labour intensity, poor occupational and environmental } \\
\text { health standards, little capital investments and lack of long-term planning,...ASM is } \\
\text { typically an informal and highly disorganized activity'. (Hinton, 2005) }\end{array}$ & $\begin{array}{l}\text { Communities and Small Scale Mining (CASM) } \\
\text { and UK Department for International } \\
\text { Development (DFID). }\end{array}$ \\
\hline
\end{tabular}




\begin{tabular}{|c|c|}
\hline $\begin{array}{l}\text { 'The majority of workers in ASM exploit small deposits in remote rural areas, from } \\
\text { where it is difficult for miners to get their goods to the market. Their work is labour- } \\
\text { intensive, low paying, extremely hazardous, and almost always avoided if other work } \\
\text { is available'. (ILO, 2003) }\end{array}$ & International Labour Organization (ILO) \\
\hline $\begin{array}{l}\text { 'A definition is fundamental in distinguishing ASGM from other mining activities. } \\
\text { While challenging, legally recognising the many different types of ASGM that exist is } \\
\text { an important tool in deciding how to address the activity and for adapting regulations } \\
\text { to appropriate levels of control for different types of activity...Ultimately, the } \\
\text { appropriate definition is best decided at the national level...' (UNEP, 2012). }\end{array}$ & United Nations Environment Program (UNEP) \\
\hline $\begin{array}{l}\text { '..at [the] global level ASM still means different things to different people... } \\
\text { Nevertheless, ASM operations all over the world share common } \\
\text { characteristics...ASGM is usually a spontaneous self-organizing social system, while } \\
\text { industrial mining is planned and centrally coordinated. Artisanal miners engage in } \\
\text { mining to earn a living, while industrial mining (large, medium and small-scale) is } \\
\text { driven by profit expectations...' (SDC, 2011) }\end{array}$ & $\begin{array}{l}\text { Swiss Agency for Development and Cooperation } \\
\text { (SDC) }\end{array}$ \\
\hline
\end{tabular}

Failure to galvanize policy interest in ASM as a poverty-driven activity would contribute to the rapid demise of the Communities and Small-Scale Mining (CASM) platform, donors' solution to calls for 'a coordinated approach to assessing and addressing some of the problems with this subsector as opposed to a piecemeal approach'. ${ }^{5}$ Born out of discussions in London in 2001 on the back of the Global Mining Initiative, ${ }^{6}$ CASM, which was initially housed at World Bank headquarters in Washington DC before moving to the DFID head office in London, was intended as a 'mouthpiece' for ASM. The broad consensus among delegates at the Millennium Development Goals and Small-Scale Mining: A Conference for Forging Partnerships for Action (World Bank, 2005) seminar in Washington DC, 16-17 June 2005, was that:

CASM, or an entity like it, is essential to ensure advocacy for the ASM sector in the international arena...[That]...without a CASM, it is unlikely that the ASM sector could generate enough international attention to attract the large donors and public advocacy necessary to improve the plight of the sector and those who rely on it for their livelihoods. [p. 17]

The umbrella organization, however, made little progress toward achieving its intended aim of 'developing policy guidelines, providing advice, disseminating best practices and experiences, raising funds and project/program implementation'. ${ }^{7}$ It proved to be a standalone initiative itself, failing to engineer the changes that need to be made to the donor machinery in order to create a viable 'space' for ASM. The lack of cohesion among various entities across different sectors committed to making ASM work was magnified during the CASM years. Moreover, the sector's continued absence on the donor agenda put the sustainability of industry support measures to the test. Its lack of stability failed to prevent the premature derailment of promising interventions such as the multimillion dollar UNIDO Global Mercury Project, and moving forward, could limit the impact of ground-breaking interventions such as the African Mining Vision. ${ }^{8}$ To claim that CASM was doomed from the outset may seem like an exaggeration but its dissolution was by no means a surprise, given its relatively autonomous existence. Its rapid demise was brought about by a combination of factors, the most significant of which will be briefly reviewed here.

First, the composition of its managerial structure seemed to be at odds with the issues being examined: namely priority concerns in the ASM sector. Apart from donor officers, many of whom had not yet embraced the ASM-poverty narrative, the CASM advisory board was comprised almost entirely of participants from the large-scale mining industry, a sector with which many ASM operators - particularly in sub-Saharan Africa - are feuding. Despite being a time when donors were increasingly making 'livelihoods' the centrepiece of lending efforts, 'the artisanal miner' remained conspicuously absent from the CASM program, and became increasingly neglected throughout its existence, reflected most clearly in the organization's flagship annual 'Learning Event'. At the inaugural Learning Event, held in Ica, Peru, 2002, efforts were made to 'underscore the relationship between miners, governments and NGOs, and to characterize contemporary beliefs on how ASM should be addressed, specifically in relation to sustainable livelihoods and community development' (Hinton, 2005, p. 2). An estimated 25 percent of attendees were miners, a figure which would drop precipitously in subsequent years.

\footnotetext{
${ }^{5}$ www.casmsite.org (Accessed 4 December 2010)

6 An international initiative, launched in 1998, by the world's nine-largest mining companies. It provided a rigorous analysis of the societal issues facing a globalizing mining sector.

7 www.casmsite.org (Accessed 4 December 2010)

8 The main aim of which was to educate small-scale gold miners about the health impacts of mercury and facilitate a change in practices.
} 


\section{DRAFT (Paper Accepted for Publication)}

By the $6^{\text {th }}$ event in Ulan Bator, Mongolia, 2007 (Expert 2, 2013), for example, only 8.5 percent of attendees were miners.

Why were artisanal miners being underrepresented at the Learning Event? The CASM executive which, rather strangely, proceeded to exclude academics and NGO officers from decision-making processes was clearly still grappling with what ASM was about, as one expert explained in a personal communication:

A major challenge was convincing the international development community including NGOs that ASM is a major development issue and depending upon how the sub-sector is approached and worked with could become a more positive force for rural community and regional development in the places where it is practiced, and that a global advocacy approach was warranted. We had the problem in the late 80s / early 90s with Small Mining International; and we had it again in the early 2000s with CASM. Could the Secretariat have been more energetic or creative in the way we approached the challenge - the answer is always 'yes'. Would it have made a difference; I am not sure. [Expert 3, 2013]

With CASM being sabotaged by consultants and industry people (Hilson, 2007), not surprisingly, there was 'a marked shift in topic discussion from hard-core technical discussions on processing, marketing, etc., towards "development" type stuff like Fair Trade and certification', a reflection of 'the dominance of outsiders to setting the ASM formalisation/development agenda' (Expert 2, 2013).

Second, for many, CASM's initial siting in Washington DC, at World Bank headquarters, presented a serious conflict of interest. With the perpetual informality of ASM, particularly in sub-Saharan Africa, being largely a result of World Bank intervention, specifically, the implementation of revised mining codes which prioritize the development of large-scale mining modelled upon recommendations prescribed in A Strategy for African Mining, the seed funding provided by CASM for, inter alia, geo-prospecting and census work in ASM communities, was little more than cosmetic. Certain governments, for example, secured grants through CASM amounting to US $\$ 25,000$, monies which could barely finance basic geological analysis. This leads to a third, and final, factor, which is the lack of funding, overall, for the cause. The Bank was unable - and perhaps unwilling - to continue financing CASM itself. Once under the management of DFID, by which time, consultants and large-scale miners had completely hijacked the executive, CASM had lost what little influence it had. Beginning in about its third year, the annual 'Learning Event' was beginning to attract more opportunistic consultants and curious onlookers than small-scale miners and representatives from organizations committed to empowering them. By this time, requests from governments in sub-Saharan Africa for funding to assist with empowering and assisting ASM groups, formalizing their activities and redrafting legislation, were routinely denied on account of there being no available finances. In less than a decade, CASM had morphed from a potentially-influential mouthpiece for ASM managed by an ambitious and energetic executive to a 'talk shop for donors and industry... [which] did not serve its primary beneficiary' (Expert 2, 2013).

To summarize, more than four decades after entering the international development lexicon, ASM remains on the periphery of poverty alleviation and local economic development policy. In the case of subSaharan Africa, failure to recognize the sector's growing economic importance has impeded its development. With poverty now widespread and employment opportunities scarce throughout the region, a formalized ASM sector could help to deliver much-needed short-term economic benefits, buying time for governments and donors to critically 're-think' how to tackle pressing development challenges. This formalization needs to take place in a policy 'space' that enables and supports flexibility and cross-sector linkages in order for the dynamics, nuances and interconnectedness of the ASM sector, especially in relation to other sectors like farming discussed earlier, to be accounted for. To accomplish this, however, a radical reorientation in policy 'mind-set' will be needed.

\section{Concluding remarks}

This paper has reflected on why, despite its economic importance, ASM continues to occupy such a marginal position on the economic development agenda of sub-Saharan Africa. A poor understanding of the sector's role in the region's liberalized economies has certainly contributed to this oversight; as has the strong influence, at the policymaking level, of unfounded ideas and generalizations about the sector's activities.

A review of ASM's policy treatment over the past four decades reveals that, in the case of sub-Saharan Africa, moves to empower the sector's operators and support its activities have been made relatively autonomously, independent of large-scale development programs. A burgeoning body of research has emerged over the past two decades which points to ASM being an indispensable - and potentially, the most important economic activity in rural sub-Saharan Africa but has failed to change donor and policymakers' perceptions of the sector completely. Until ample 'space' is created for ASM in regional economic development policy, efforts to support its activities and operators will continue to yield disappointing results. 


\section{DRAFT (Paper Accepted for Publication)}

\section{References}

Ackah-Baidoo, A. 2012. Enclave development and 'offshore corporate social responsibility': Implications for oil-rich sub-Saharan Africa. Resources Policy 37(2): 152-159.

Ali, S.V. 1986. Small Scale Mining - Towards a Purposive Definition? Journal of Mines, Metals and Fuels 39(8-9): 401-404.

Alpan, S., 1986. The role of government in promoting small-scale mining. Natural Resources Forum 10 (1), 9597.

Anyinam, C. A. 1989. The social costs of the International Monetary Fund's adjustment programs for poverty: the case of health care development in Ghana. International journal of health services, Vol.19, No. 3, p.531-547.

Banchirigah, M. S. 2006. How have reforms fuelled the expansion of artisanal mining? Evidence from subSaharan Africa. Resources Policy, Vol. 31, No. 3. pp. 165-171.

Bank of Ghana. 2003. Report on the Mining Sector. Bank of Ghana Report No 1(3). Accra: Bank of Ghana.

Barry, M. (Ed.), 1996. Regularizing Informal Mining. A Summary of the Proceedings of the International Roundtable on Artisanal Mining. Organized by the World Bank, 17-19, May 1995, Industry and Energy Department Occasional Paper No. 6, Washington, DC.

Binns, J. 1982. Agricultural change in Sierra Leone. Geography 67(2): 113-125.

Bleischwitz, R., Dittrich, M. \& Pierdicca, C. 2012. Coltan from Central Africa, international trade and implications for any certification. Resources Policy, 37(1): 19-29.

Bosson, R., Varon, B. 1978. The Mining Industry and the Developing Countries. World Bank. Washington D.C.

Bugnosen, E.M. 1998. A Preliminary Assessment of Small-Scale Mining Legislation and Regulatory Frameworks. Department for International Development (DFID), Intermediate Technology Development Group, UK.

Buxton, A. 2013. Sustainable Markets. Responding to the challenges of artisanal and small-scale mining. How can knowledge networks help? International Institute of Environment and Development (IIED). London.

Campbell, B. 2001. Better Resource Governance in Africa: On What Development Agenda? Minerals and Energy: Raw Materials Report 21( 3-4): 3-18.

Campbell, B. 2003. Factoring in governance is not enough: Mining codes in Africa, policy reform and corporate responsibility. Minerals and Energy: Raw Materials Report 18(3): 2-13.

Carman, J.S. 1987. Why Small Mining? Episodes 10(3): 159-164.

Chachage, C.S.L. 1993. New Forms of Accumulation in Tanzania: The Case of Gold Mining, p. 79-105, in Mining and Structural Adjustment: Studies on Zimbabwe and Tanzania (ed. C.S.L. Chachage et al.), Research Report 92, Nordiska Afrikainstitutet, Uppsala.

Chachage, C. S. L. 1995. The Meek Shall Inherit the Earth but not the Mining Rights: The Mining Industry and Accumulation in Tanzania, in P. Gibbon (ed.) Liberalised Development in Tanzania, pp. 37-108. Uppsala: Nordiska Afrikainstitutet.

Cornia, G.A., Jolly, F., Stewart, F. 1987. Adjustment with Human Face: Protecting the Vulnerable and Promoting Growth. Oxford University Press. Oxford.

Davidson, J., 1993. The transformation and successful development of small-scale mining enterprises in developing countries. Natural Resources Forum 17(4):315-326. 


\section{DRAFT (Paper Accepted for Publication)}

Dreschler, B. 2001. Small-scale Mining and Sustainable Development within the SADC Region. Mining, Minerals and Sustainable Development (MMSD). International Institute for Environment and Development and World Business Council for Sustainable Development. London.

Eicher, C. 2003. Flashback: Fifty Years of Donor Aid to African Agriculture. Paper presented at Successes in African Agriculture, InWEnt, IFPRI, NEPAD, CTA Conference, Pretoria.

Expert 1. 2013. Personal Communication. 17 November 2013.

Expert 2. 2013. Personal Communication. 25 November 2013.

Expert 3. 2013. Personal Communication. 10 June 2013.

Ferguson, J. 2005. Seeing Like an Oil Company: Space, Security, and Global Capital in Neoliberal Africa. American Anthropologist 107(3): 377-382.

Fisher, E. 2007. Occupying the Margins: Labour Integration and Social Exclusion in Artisanal Mining in Tanzania. Development and Change 38(4): 735-760.

Free the Slaves. 2013. Congo's Mining Slaves, Enslavement at South Kivu Mining Sites. Investigative Field Report, Free The Slaves, Washington DC.

Hentschel, T., F. Hruschka, Priester, M. 2002. Global Report on Artisanal and Small-Scale Mining, Minerals Mining and Sustainable Development (MMSD) Project. International Institute for Environmental Development, London

Hilson, G. 2002. Delivering aid to grassroots industries: a critical evaluation of small-scale mining support services. Minerals and Energy 17(1): 11-18.

Hilson, G. 2002. Small-scale mining in Africa: tackling pressing environmental problems with improved strategy. Journal of Environment and Development 11(2): 149-174.

Hilson, G. 2007. What is wrong with the Global Support Facility for small-scale mining? Progress in Development Studies 7(3): 235-249.

Hilson, G. 2008. 'A load too heavy': Critical reflections on the child labor problem in Africa's small-scale mining sector. Children and Youth Services Review 30: 1233-1245.

Hilson, G. 2009. Small-scale mining, poverty and economic development in sub-Saharan Africa: An overview. Resources Policy 34(1-2).1-5.

Hilson , G. 2010. 'Once a miner, always a miner': Poverty and livelihood diversification in Akwatia, Ghana. Journal of Rural Studies. 26: 296-307.

Hilson, G., Amankwah, R., Ofori-Sarpong, G. 2013. Going for gold: transitional livelihoods in Northern Ghana. The Journal of Modern African Studies 51(1): 109-137.

Hilson, G., Pardie, S. 2006. Mercury: An agent of poverty in Ghana's small-scale gold-mining sector? Resources Policy 31(2): 106-116.

Hilson, G., Potter, C. 2005. Structural adjustment and subsistence industry: artisanal gold mining in Ghana. Development and Change 36(1): 103-131.

Hinton, J. J. 2005. Communities and Small-Scale Mining: An Integrated Review for Development Planning. Communities and Small-Scale Mining (CASM) Initiative Report. World Bank, Washington DC.

Human Rights Watch. 2013. Toxic Toil. Child Labour and Mercury Exposure in Tanzania's Small-Scale Gold Mines. Human Rights Watch. USA. 


\section{DRAFT (Paper Accepted for Publication)}

Husain, I., Faruqee, R. 1994. Adjustment in Africa: Lessons from country case studies. World Bank, Washington D.C.

International Council on Mining and Metals (ICMM). 2010. Working Together: How large-scale mining can engage with artisanal and small-scale miners. International Council on Mining and Metals, London.

International Labour Organisation (ILO). 1999. Social and labour issues in small-scale mines. Report for discussion at the Tripartite Meeting on Social and Labour Issues in Small-scale Mines. International Labour Organization, Sectoral Activities Program, International Labour Office, Geneva.

International Labour Organisation (ILO). 2003. Facts on Small-scale Mining. www.ilo.org/global/resources/WCMS_067582/lang--en/index.htm (Accessed 11 November 2013).

International Monetary Fund (IMF). 2003 An Agenda for Growth and Prosperity. IMF, Washington DC.

International Monetary Fund (IMF). 2005. National Strategy for Growth and Reduction of Poverty. IMF, Washington DC.

International Monetary Fund (IMF). 2006. National Strategy for Growth and Reduction of Poverty. IMF, Washington DC.

International Monetary Fund (IMF). 2011. National Strategy for Growth and Reduction of Poverty II. IMF, Washington DC.

Jennings, N.S. 2003. Addressing labour and social issues in small-scale mining, p. 151-160, in The SocioEconomic Impacts of Artisanal and Small-Scale Mining in Developing Countries (ed. G.M. Hilson). A.A. Balkema, The Netherlands.

Kamlongera, P., Hilson, G. 2011. Making the poor 'poorer' or alleviating poverty? Artisanal mining livelihoods in rural Malawi. Journal of International development 23(8): 1128-1139.

Khan, S. L. A. 2010. Poverty Reduction Strategy Papers: failing minorities and indigenous peoples. Minority Rights Group International. London.

Kumar, R., Amaratunga, D. 1994. Government policies towards small-scale mining. Resources Policy 20(1): 15-22.

Lancaster, C. 1999. Aid to Africa: So Much to Do, So Little Done. University of Chicago Press, Chicago.

Labonne, B. 1999. The mining industry and the community: Joining forces for sustainable social development. Natural Resources Forum 23(4): 315-322.

Maconachie, R. 2009. Diamonds, governance and 'local' development in post-conflict Sierra Leone: Lessons for artisanal and small-scale mining in sub-Saharan Africa? Resources Policy 34(1-2): 71-79.

Maconachie, R. 2011. Re-agrarianising livelihoods in post-conflict sierra leone? Mineral wealth and rural change in artisanal and small-scale mining communities. Journal of International Development 23(8): 10541067.

McDivitt, J. F. 1990. Small-Scale Mining: A Guide to Appropriate Equipment. Intermediate Technology and Development Group (ITDG) Publishing, London.

Mohan, G. 2000. Contested Sovereignty and Democratic Contradictions: The Political Impacts Adjustment, p. 75-95, in Structural Adjustment: Theory, Practice and Impacts (ed. G. Mohan et al), Routledge, London

Mosley, P., Smith, L. 1989. Structural adjustment and agricultural performance in Sub-Saharan Africa 1980-87. Journal of International Development 1(3): 321-355.

Maponga, O., Ngorima, C.F. 2003. Overcoming environmental problems in the gold panning sector through legislation and education: the Zimbabwean experience. Journal of Cleaner Production 11(2): 147-157. 


\section{DRAFT (Paper Accepted for Publication)}

Maldar, S. 2011. Fairtrade and Fairmined Gold, Empowering responsible artisanal and small-scale miners. Fairtrade Foundation and Alliance for Responsible Mining Report, London

Mugova, A. 2001. Presentation: The Shamva Mining Centre Project. Mining, Minerals and Sustainable Development (MMSD) Project, International Institute for Environment and Development, London.

Mutemeri, N., Petersen, F. 2002. Small-scale mining in South Africa: Past, present and future. Natural Resources Forum 26: 286-292.

Nicholas, P. 1988. Adjustment and the poor: The role of the World Bank. Food Policy 13(1): 83-89

Noetstaller, R. 1987. Small-Scale Mining: A Review of the Issues. World Bank Technical Paper Number 75. Industry and Finance Series. The World Bank, Washington D.C.

Noetstaller, R. 1994. Small-scale mining: practices, policies and perspectives, in Small-scale Mining: A Global Overview (ed. A.K. Ghose). A.A. Balkema, Rotterdam.

Noorbakhsh, R., Paloni, A. 2001. Structural Adjustment and Growth in sub-Saharan Africa: The Importance of Complying with Conditionality. Economic Development and Cultural Change 49(3): 479-509.

Parsons, L. B. 1996. Engineering in Context: Engineering in Developing Countries. Journal of Professional Issues in Engineering Education and Practice 122(4): 170-176.

Peak, A.V., Johnson, R.A., Svotwa, R. 1998. A perspective on the provision of technical expertise to the small scale mining industry in southern Africa, pp. 127-132, in Mining in Africa '98, South African Institute of Mining and Metallurgy, Johannesburg.

Priester, M., Hentschel, T., 1992. Small-scale gold-mining: Processing techniques in developing countries. Vieweg, Braunschweig.

Riddell, R. 1992. Judging Success: Evaluating NGO Approaches To Alleviating Poverty In Developing Countries. ODI Working Paper 37. ODO. London.

Swiss Agency for Development and Cooperation (SDC). 2011. SDC experiences with Formalization and Responsible Environmental Practices in Artisanal and Small-scale Gold Mining in Latin America and Asia (Mongolia). Swiss Federal Department of Foreign Affairs FDFA, Swiss Agency for Development and Cooperation SDC. Bern.

Spiegel, S.J. 2009. Resource policies and small-scale gold mining in Zimbabwe. Resources Policy 34: 39-44.

Spiegel, S., Veiga, M. 2010. International guidelines on mercury management in small-scale gold mining. Journal of Cleaner Production 18(4): 375-385.

United Nations (UN). 1972. Small-Scale Mining in the Developing Countries. United Nations, New York.

United Nations (UN). 1996. Recent developments in small-scale mining: A report of the Secretary-General of the United Nations. Natural Resources Forum. 20(3): 215-225.

United Nations Department of Economic and Social Affairs (UNDESA). 2003. Poverty Eradication \& Sustainable Livelihoods: Focusing on Artisanal Mining Communities. SPPD Project RAF/99/023. Final Report, United Nations Department of Economic and Social Affairs (UNDESA), New York.

United Nations Economic Commission for Africa (UNECA). 2003. Reports on Selected Themes in Natural Resources Development in Africa: Artisanal and Small-Scale Mining and Technology Challenges in Africa. United Nations Economic Commission for Africa (UNECA), Addis Ababa.

United Nations Economic Commission for Africa (UNECA). 2011. Minerals and Africa's Development: The International Study Group Report on Africa's Mineral Regimes. United Nations Economic Commission for Africa and African Union, Addis Ababa, Ethiopia. 


\section{DRAFT (Paper Accepted for Publication)}

United Nations Environment Programme (UNEP). 2012. Analysis of formalization approaches in the artisanal and small-scale gold mining sector based on experiences in Ecuador, Mongolia, Peru, Tanzania and Uganda. United Nations Environment Programme, Division of Technology, Industry and Economics (DTIE), Chemical Branch, Geneva, Switzerland.

Wamalwa, W.N.W. 1995. Some Reflections on the Experience of Foreign Aid. Development Dialogue 2: 1220 .

Weber-Fahr, M. 2002. Treasure or Trouble? Mining in Developing Countries. Mining and Development Series. Washington, D.C.: World Bank/International Finance Corporation.

Wels, T.A. 1983. Small-scale mining - The forgotten partner. Transactions of the Institution of Mining an Metallurgy 92(1): A19-A27.

World Bank. 1979. Bolivia - National Mineral Exploration Fund Project. World Bank, Washington DC.

World Bank. 1979. Bolivia - National Mineral Exploration Fund Project. World Bank, Washington, DC.

World Bank. 1989. Sub-Saharan Africa, From Crisis to Sustainable Growth: A Long Term Perspective Study . World Bank, Washington DC.

World Bank .1992. A Strategy for African Mining. World Bank, Washington DC.

World Bank. 2005. Millennium Development Goals and Small-Scale Mining: A Conference for Forging Partnerships for Action. World Bank, Washington DC.

World Bank. 2013. The World Bank. Oil, Gas, Mining Unit. Small-Scale Mining, Communities and SmallScale Mining (CASM) Initiative. http://go.worldbank.org/4K0MT244R0 (Accessed 24 November 2013). 